\title{
CD95 engagement mediates actin-independent and -dependent apoptotic signals
}

\author{
B Chaigne-Delalande ${ }^{1,2,3}$, W Mahfouf ${ }^{1,2,3}$, S Daburon ${ }^{1,2,3}$, J-F Moreau $^{1,2,3,4}$ and P Legembre ${ }^{\star, 1,2,3}$
}

CD95 is a death receptor whose stimulation by either the physiologic ligand CD95L or the agonistic antibodies leads to the formation of a multi-molecular complex termed DISC (death-inducing signaling complex) and the subsequent induction of a caspase-driven apoptotic signal. According to the magnitude of the DISC formation, two types of cells have been identified. Although type I cells generate an important DISC, the complex is barely found in type II cells. Analyzing the early stages preceding the DISC formation, we found that unlike CD95L, the commonly used agonistic antibody APO1-3 internalized the death receptor. Using inhibitors of actin polymerization, we showed that the remodeling of the actin cytoskeleton did not alter the capping of the CD95 receptor or its partitioning into the lipid rafts. In addition, whereas the disruption of F-actin prevented the internalization of CD95, the DISC formation and the apoptotic signal induced by the agonistic antibody AP01-3 in type I cells, it did not affect the signal triggered by the soluble and membrane-bound CD95L, regardless of the type of cells. In conclusion, the addition of AP01-3 on type I cells triggers an actin-dependent apoptotic signal, which is absent or marginal in cells (both types I and II) treated with CD95L.

Cell Death and Differentiation (2009) 16, 1654-1664; doi:10.1038/cdd.2009.111; published online 14 August 2009

The receptor CD95 (Fas/APO1) belongs to the tumor necrosis factor (TNF)-R superfamily having an essential role in lymphocyte homeostasis and in the elimination of infected or transformed cells. CD95 is expressed as a pre-associated homotrimer at the cell membrane ${ }^{1}$ and both aggregation and conformational modifications have been suggested as important to induce the apoptotic signal. ${ }^{2}$ The cognate ligand of CD95, CD95L is a type II transmembrane protein, which is found soluble after cleavage by metalloproteases. ${ }^{3}$ The intracellular region of CD95 encompasses an 80 amino acid long stretch called the death domain. On binding with CD95L or agonistic antibodies, the death domain of CD95 recruits the adaptor protein, Fas-associating protein with death domain (FADD), which in turn aggregates the procaspase-8 and -10 . The complex CD95/FADD/caspases-8/-10 is termed the DISC for death-inducing signaling complex. ${ }^{4}$ This platform is crucial to release active caspases in the cytosol and to propagate the apoptotic signal. Cells have been classified as type I, in which the DISC is efficiently formed, and type II, in which the formation of the complex is impaired for still unknown reasons.

The expression of CD95L is tightly controlled and the apoptotic cytokine is found expressed at the plasma membrane of activated T lymphocytes ${ }^{5}$ and NK (natural killer) cells ${ }^{6}$ with the object of eliminating infected and transformed cells. In addition, chemotherapeutical drugs can cause the upregulation of CD95L at the surface of the malignant cells, which are thereby eliminated through an autocrine and/or a paracrine process. ${ }^{7}$ Tumor cells fall into two distinct branches sharing a similar pattern of gene expression, the epithelium-like and the mesenchymal-like cells. ${ }^{8}$ The epithelial-mesenchymal transition (EMT) has been reported to occur during carcinogenesis. ${ }^{9}$ Strikingly the so-called type I cells show mesenchymal markers, whereas the type II cells correspond to the branch expressing epithelial genes. ${ }^{8}$ As a consequence, the correlation between the efficiency of DISC formation and EMT suggests that carcinogenesis could affect the initial steps of the CD95 signal to prevent death signaling and hence to escape the immune system and/or the antitumoral chemotherapy.

Various scenarios have been reported to account for the formation of the DISC such as the production of ceramide, CD95 clathrin-dependent internalization, palmitoylation and/ or its partitioning into lipid rafts. ${ }^{10}$ The clathrin-dependent endocytosis of CD95 requires the reorganization of the actin network to internalize and to transport the coated vesicles. By facilitating the spatial redistribution of CD95 into the early endosomes, endocytosis has been suggested to initiate the formation of the DISC in type I cells. ${ }^{11}$ Nevertheless, contradictory studies have reported that the actin cytoskeleton network was not involved in the CD95-mediated apoptotic signal, ${ }^{12,13}$ indicating that the function of actin in the CD95mediated apoptotic signal needs to be clarified.

Stimulation of CD95 using either its physiological ligand, CD95L, or the agonistic antibodies has revealed differences in the way the apoptotic signal was transmitted. ${ }^{14-16}$ For instance,

${ }^{1}$ CNRS UMR 5164, 146 rue Léo Saignat, Bordeaux 33076, France; ${ }^{2}$ Université de Bordeaux-2, 146 rue Léo Saignat, Bordeaux 33076, France; ${ }^{3}$ IFR66, 146 rue Léo Saignat, Bordeaux 33076, France and ${ }^{4} \mathrm{CHU}$ Bordeaux, Place Amélie Raba Léon, Bordeaux 33076, France

${ }^{*}$ Corresponding author: P Legembre, CNRS UMR 5164, Université de Bordeaux-2, 146 rue Léo Saignat, Bordeaux 33076, France.

Tel: + 335575711 24; Fax: + 335575714 72; E-mail: patrick.legembre @inserm.fr

Keywords: CD95; DISC; signal; actin; endocytosis

Abbreviations: CytD, cytochalasin D; DAPI, 4',6-diamidino-2-phenylindole; DiOC6, 3,3'-dihexyloxacarbocyanine iodide; DISC, death-inducing signaling complex; EMT, epithelial-mesenchymal transition; FADD, Fas-associating protein with death domain; LtnA, latrunculin A; MTT, 3-(4,5-dimethylthiazol-2-yl)-2,5diphenyltetrazolium bromide; PBS, phosphate-buffered saline; PBT, peripheral blood T lymphocyte; SDS-PAGE, sodium dodecyl sulfate-polyacrylamide gel electrophoresis; TNF, tumor necrosis factor; WGA, wheat germ agglutinine

Received 17.2.09; revised 09.7.09; accepted 09.7.09; Edited by A Villunger; published online 14.8.09 
a

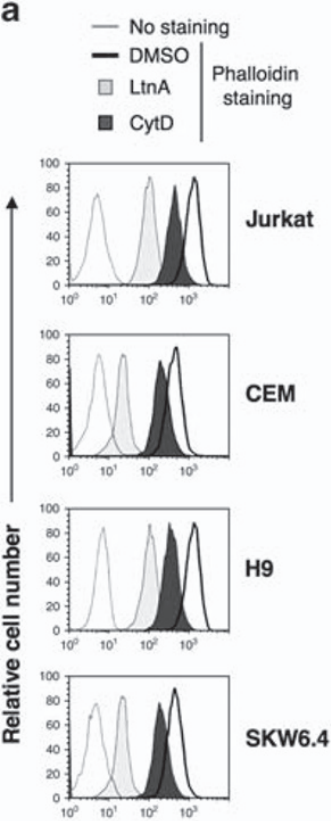

Phalloïdin binding (MFI)

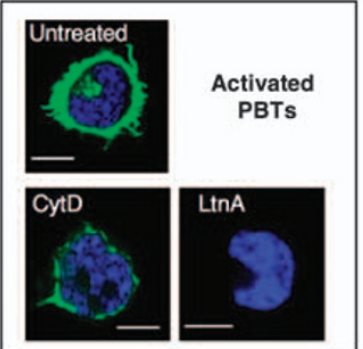

b

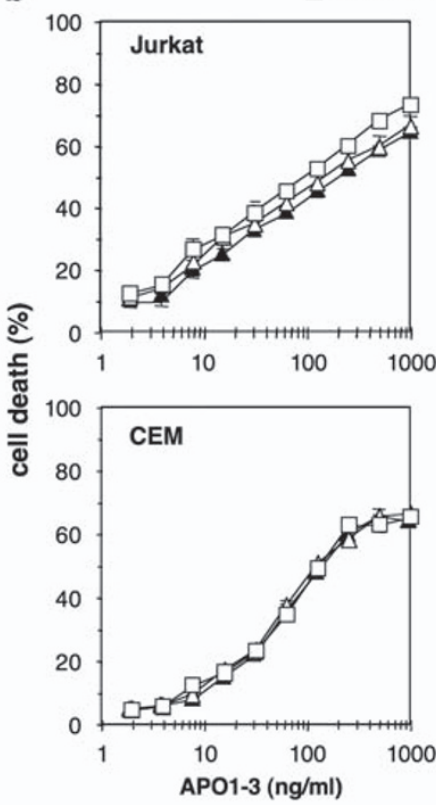

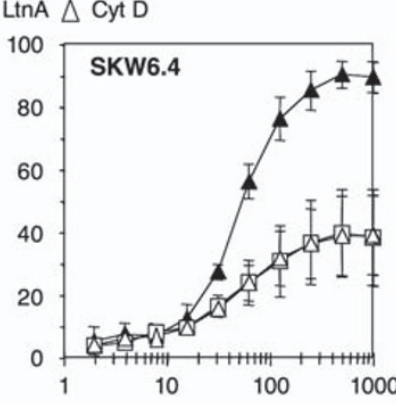
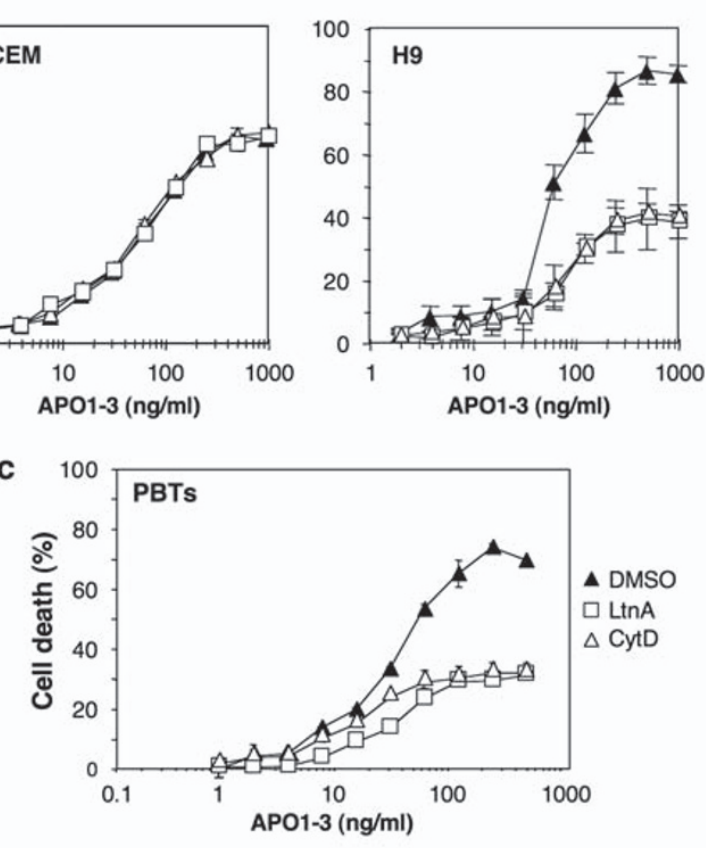

d $\quad$ CEM $\triangle \mathrm{H} 9$ 口 Jurkat $\triangle$ SKW6.4

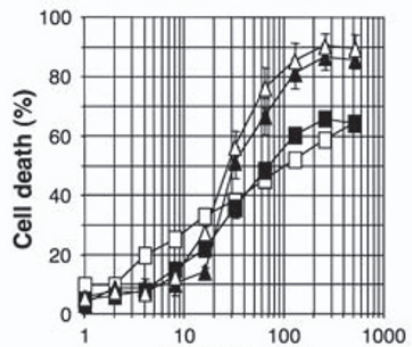

APO1-3 $(\mathrm{ng} / \mathrm{ml})$
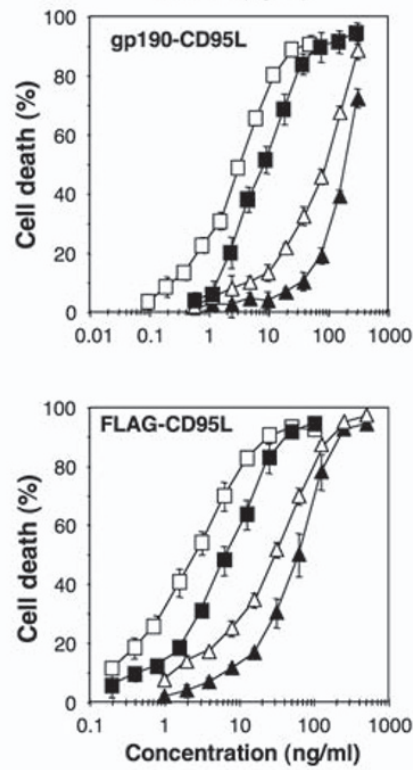

Figure 1 The agonist anti-CD95 mAb AP01-3 induces actin-dependent and -independent apoptotic signals. (a) The activated T lymphocytes from healthy donors (PBTs), the type I cell lines SKW6.4 and H9 and the type II cell lines Jurkat and CEM were treated with latrunculin A (LtnA, $2.5 \mu \mathrm{M})$, cytochalasin D (CytD, $5 \mu \mathrm{M})$ or DMSO for 30 min. Cells were fixed and permeabilized and F-actin was stained with FITC-coupled phalloidin. The cell fluorescence was assessed using flow cytometry analysis (top panels) or confocal microscopy (bottom panel, Bar $=5 \mu \mathrm{m}$ ). (b) Type I (H9, SKW6.4) and type II (Jurkat, CEM) cell lines were treated with LtnA (2.5 $\mu \mathrm{M})$, CytD (5 $\mu \mathrm{M})$ or DMSO for $30 \mathrm{~min}$. Then cells were incubated for $24 \mathrm{~h}$ with indicated concentrations of the agonist anti-CD95 mAb APO1-3 and cell death was quantified by using an MTT assay. (c) Activated PBTs were treated exactly as described above. (d) Type I (H9, SKW6.4) and type II (Jurkat, CEM) cells were treated for $24 \mathrm{~h}$ with indicated concentrations of AP01-3 or two forms of multimeric CD95L (FLAG-CD95L and gp190-CD95L). Cell death was assessed using the viability MTT assay. Results shown represent the mean \pm S.D. of three independently performed experiments

the incubation of leukemic cells or activated peripheral blood $T$ lymphocytes (PBTs) with agonistic antibodies led to the formation of CD95 microaggregates, whereas CD95L did not. ${ }^{15}$ Herein, we investigated the role of the actin cytoskeleton on the initial events preceding the formation of the DISC. Although CD95 internalization was essential to trigger the apoptotic signal induced by the commonly used agonistic antibody APO1-3, soluble and membrane-bound CD95L did not lead to CD95 endocytosis. The findings obtained with the inhibitors of actin polymerization underscored that CD95 is able to induce at least two types of apoptotic signal (actin-dependent and independent), which rapidly diverged before the DISC formation.

\section{Results}

The agonist anti-CD95 mAb APO1-3 induces an actindependent apoptotic signal in type I cells. To address the role of actin in the CD95-mediated apoptotic signal, we analyzed the effect of two well-characterized inhibitors of the actin polymerization on the CD95-mediated apoptotic signal: latrunculin $A(\operatorname{Ltn} A)$ and cytochalasin $D(C y t D)$. Alteration of the actin polymerization by these chemicals was assessed in each cell type tested (Figure 1a). The use of a fluorochromecoupled phalloidin on permeabilized cells enabled the quantification of F-actin by flow cytometry (Figure 1a, top panel) or confocal microscopy (Figure 1a, bottom panel). Non-toxic doses of CytD and LtnA decreased the quantity of polymerized actin in SKW6.4, H9 and activated PBTs (type I cells) and CEM and Jurkat (type II cells). The CD95-mediated apoptotic signal triggered by the agonist antibody APO1-3 was impaired by the inhibition of actin polymerization in the type I cells (SKW6.4, H9), whereas it remained unaffected in the type II cells (Jurkat, CEM) (Figure 1b). Similar to SKW6.4 and H9, the AP01-3induced CD95 signal in the activated PBTs was 
a

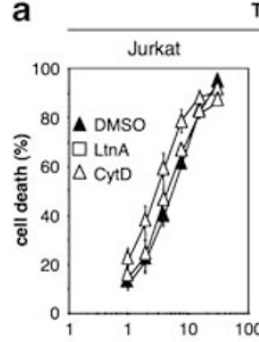

CD95L (ng/mL)

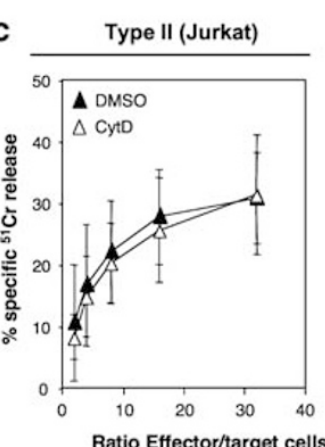

Type II

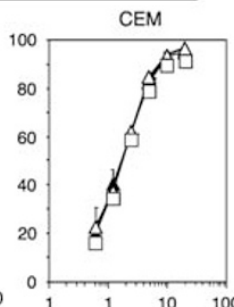

$10 \quad 100$

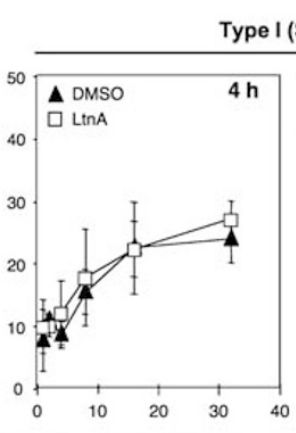

Type I

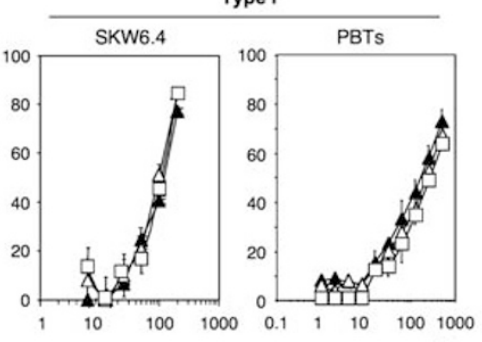

$\longrightarrow$ b $\quad \Delta$ Control $\square$ LtnA $\triangle$ CytD Type II

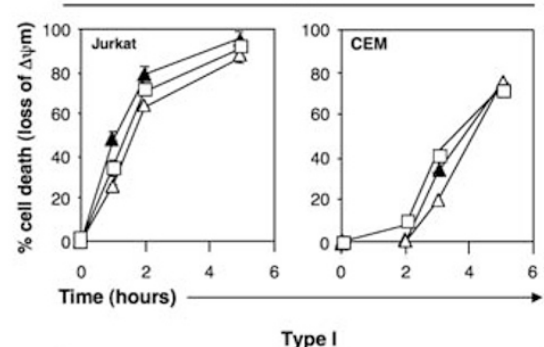

Type I
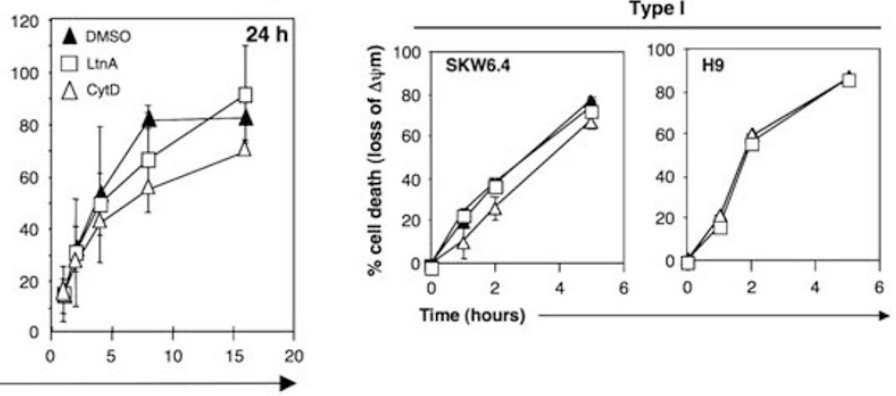

Figure 2 Soluble and membrane-bound CD95 triggers an actin-independent apoptotic signal. (a) Type I (H9, SKW6.4) and type II (Jurkat, CEM) cells were treated with latrunculin $\mathrm{A}(\mathrm{LtnA}, 2.5 \mu \mathrm{M})$, cytochalasin D (CytD, $5 \mu \mathrm{M})$ or DMSO for $30 \mathrm{~min}$. Then cells were incubated with indicated concentrations of soluble FLAG-CD95L for $24 \mathrm{~h}$. Cell death was quantified by MTT. (b) Indicated cells were loaded with DiOC6 before incubation with LtnA $(2.5 \mu \mathrm{M})$, CytD $(5 \mu \mathrm{M})$ or DMSO for 30 min. Cells were then incubated with $10 \mathrm{ng} / \mathrm{ml}$ (Jurkat, CEM) or $100 \mathrm{ng} / \mathrm{ml}\left(\mathrm{H} 9\right.$, SKW6.4) of soluble CD95L for the indicated times. The proportion of cells whose mitochondrial potential $\left(\Delta \Psi_{\mathrm{m}}\right)$ had dropped was quantified by flow cytometry. (c) Target cells (Jurkat or SKW6.4) were loaded with ${ }^{51} \mathrm{Cr}$ for $1 \mathrm{~h}$, washed and then pre-incubated with LtnA $(2.5 \mu \mathrm{M})$, CytD (5 $\left.\mu \mathrm{M}\right)$ or DMSO for $30 \mathrm{~min}$. Cells were mixed with effectors cells at the indicated ratio and the percentage of ${ }^{51} \mathrm{Cr}$ release was measured and correlated to cell death. Results shown represent the mean \pm S.D. of three independently performed experiments

significantly diminished by the blockade of actin polymerization (Figure 1c). These findings underlined that the implication of F-actin in the CD95 signal is restricted to the type I cells, as the disruption of the actin cytoskeleton network did not modify the CD95-mediated apoptotic signal in type II cells. Although the type I and type II cells responded similarly to the apoptotic inducer APO1-3 with an ED50 comprised between 21 and $35 \mathrm{ng} / \mathrm{ml}$ for each tested type I (H9/SKW6.4) and type II cells (Jurkat/CEM) (Figure 1d), the two groups were easily distinguished by their sensitivity to different forms of soluble CD95L (Figure 1d). Indeed, the type II cells were more efficiently killed than the type I cells (and PBTs) by the addition of CD95L (Figure 1d). As the actin cytoskeleton in type II cells did not participate in the CD95 signal (Figure 1b) and the physiological ligand CD95L was much more efficient in killing type II cells than type I cells (Figure 1d), we next investigated whether CD95L required an actin-dependent process to signal apoptosis.

Membrane-bound and soluble CD95 trigger an actinindependent apoptotic signal. Similar to APO1-3, the soluble CD95 $\mathrm{L}^{15}$ induced cell death independently of actin in type II cells (Jurkat/CEM) (Figure 2a). Strikingly and in contrast to APO1-3, the disturbance of actin polymerization in type I cells did not modify the CD95 signal induced by the addition of the soluble CD95L (Figure 2a). We hypothesized that the remodeling of actin may act as a catalyst that modulated the kinetics but not the intensity of the CD95 signal, and hence a 24-h incubation with CD95L may have been too long to observe the effect of actin polymerization on the apoptotic signal. To explore this possibility, we examined the impact of LtnA and CytD on the CD95 signal using shorter incubation times. Similar to the 24-h incubation, soluble CD95L eliminated both type I and type II cells independently of the actin cytoskeleton at shorter incubations as well (Figure 2b). Identical findings were obtained with the recombinant human FLAG-CD95L (rhCD95L, Supplementary Figure 1a). Our homemade soluble CD95L is a dodecameric ligand (data not shown) that could behave differently from the physiological membrane-bound CD95L. Therefore, we next investigated the effect of membrane-bound CD95L in the presence of inhibitors of actin polymerization. Identical to the soluble CD95L, the membrane-bound CD95L induced a cell death signal independently of the reorganization of the actin network in both short and long incubations (Figure 2c). Membrane-bound CD95L can be cleaved by metalloproteases and released in the serum as a soluble ligand. ${ }^{3}$ It was thus conceivable that the actin-independent signal observed with CD95L-expressing cells was because of the cleaved form instead of the membrane-bound CD95L. Therefore, to rule out this possibility, we blocked the CD95L cleavage by incubating the cells with GM6001, the large spectrum inhibitor of metalloproteases. Although the treatment enhanced both the amount of the membrane-bound CD95L (Supplementary Figure 1b) and the apoptotic signal, the inhibition of actin polymerization remained inefficient to alter the apoptotic signal (Supplementary Figure 1c). In conclusion, the soluble and membrane-bound CD95L behaved differently from the agonist antibody APO1-3 in switching on an actinindependent apoptotic signal in type I cells. 
a

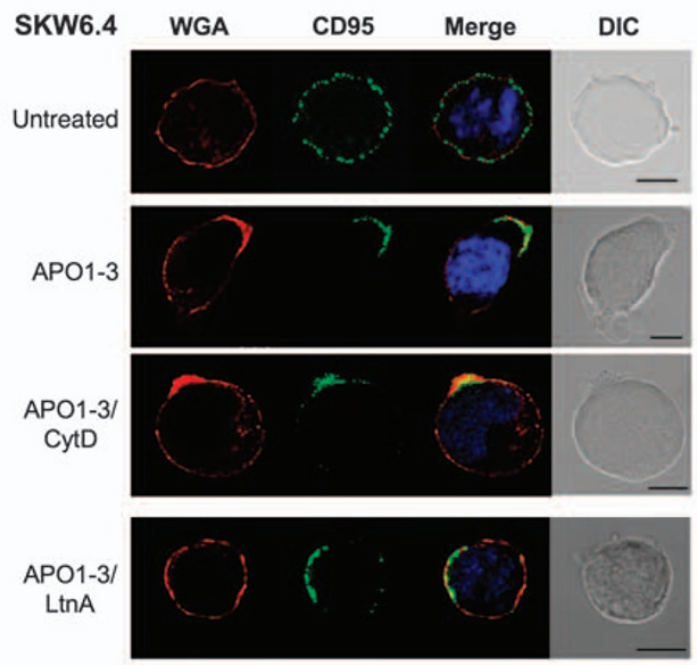

Activated PBTs

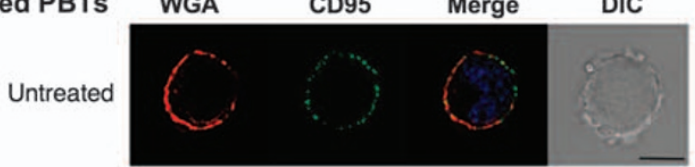

APO1-3

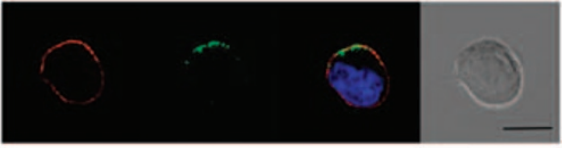

APO1-3 CytD

AP01-3/

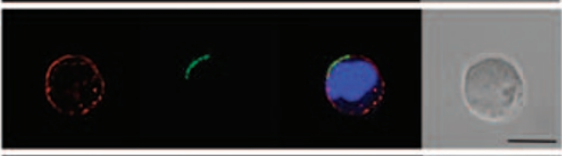

LtnA

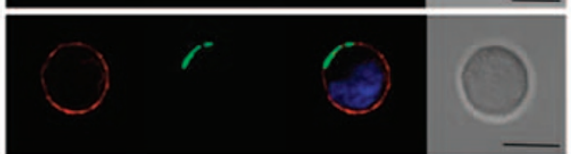

b

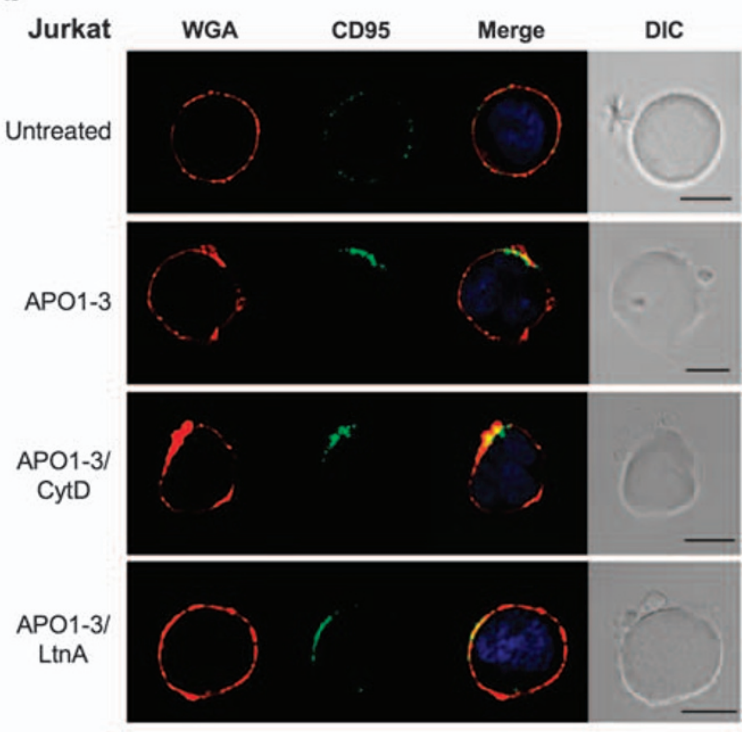

C

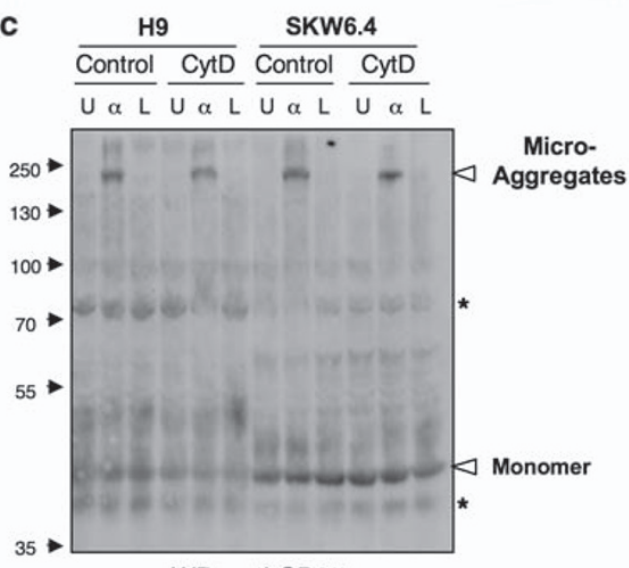

WB: anti-CD95

Figure 3 Actin does not have a role on the formation of CD95 microaggregates or the CD95 capping. (a) The type I cells (SKW6.4 and activated peripheral blood lymphocytes) were treated with cytochalasin $\mathrm{D}(\mathrm{CytD}, 5 \mu \mathrm{M})$, latrunculin $\mathrm{A}(\mathrm{LtnA}, 2.5 \mu \mathrm{M})$ or DMSO for $30 \mathrm{~min}$ at $37^{\circ} \mathrm{C}$ and then incubated with the agonist anti-CD95 $\mathrm{mAb}$ AP01-3 $(1 \mu \mathrm{g} / \mathrm{ml})$ at $4^{\circ} \mathrm{C}$ (unstimulated) or at $37^{\circ} \mathrm{C}$ (APO1-3) for $15 \mathrm{~min}$. Cells were fixed, and CD95 was revealed with the secondary Alexa488-coupled Goat anti-mouse antibody and analyzed by confocal microscopy. Contour of the plasma membrane was followed using differential interference contrast microscopy (DIC) and staining with the carbohydrate-binding protein WGA coupled to the fluorescent dye Alexa647. Nuclei were stained with DAPI (blue), Bar $=7.5 \mu$ m. (b) The type II cell line Jurkat was treated exactly as described above, Bars $=7.5 \mu \mathrm{m}$. (c) Indicated cells were incubated with CytD $(5 \mu \mathrm{M})$ or DMSO for $30 \mathrm{~min}$. Cells were then untreated (U), or treated with soluble $100 \mathrm{ng} / \mathrm{ml}$ of CD95L (L) or $1 \mu \mathrm{g} / \mathrm{ml}$ of APO1-3 mAb $(\alpha)$ for $60 \mathrm{~min}$. Cells were lysed and $100 \mu \mathrm{g}$ of protein was resolved by SDS-PAGE. Asterisks indicate irrelevant bands. CD95 was revealed by immunoblot. Results shown are representative of three independent experiments

Actin acts neither on the formation of CD95 microaggregates nor on the CD95 capping. The initial events preceding the formation of the DISC and the subsequent activation of the initiator caspase-8 on CD95 stimulation have been described partially. ${ }^{10}$ To identify the stage where the apoptotic signals induced by CD95L and APO1-3 diverged, we analyzed the factor targeted by the actin cytoskeleton during the initial events of the CD95 signaling.

CD95 stimulation leads to the rapid (1-10 min) formation of a micrometer-sized CD95 platform termed 'CD95 capping' observable by confocal microscopy. ${ }^{17}$ In the type I cells SKW6.4 and activated PBTs, the formation of the CD95 clusters on APO1-3 stimulation was not altered by the disruption of F-actin (Figure 3a). The clustering of CD95 was also observed in the type II cell line Jurkat and, similar to type I cells, this megastructure remained unaffected despite the blocking of actin polymerization (Figure 3b). Afterward, CD95 activation drives the formation of heavy molecular complexes that migrate at $200-250 \mathrm{kDa}$ in sodium dodecyl sulfate-polyacrylamide gel electrophoresis (SDS-PAGE), which are not dispersed by boiling in SDS and which resist reducing agents. ${ }^{18}$ These structures are called CD95 microaggregates and are observed between 10 and $30 \mathrm{~min}$ after CD95 stimulation in type I (Figure 3c). As stated by us earlier, ${ }^{15}$ although the agonist antibody APO1-3 induced the formation of the CD95 microaggregates, soluble CD95L was unable to generate the heavy complex (Figure 3c). In addition, CytD and LtnA did not impair the formation of these highly resistant structures (Figure $3 c$ and data not shown). These findings led us to conclude that the actin cytoskeleton does not 
a

Jurkat

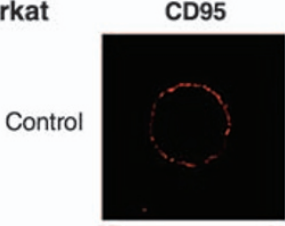

CD95L

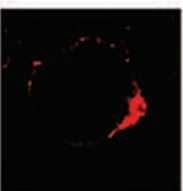

APO1-3

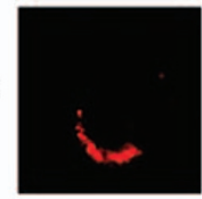

b

H9

Control
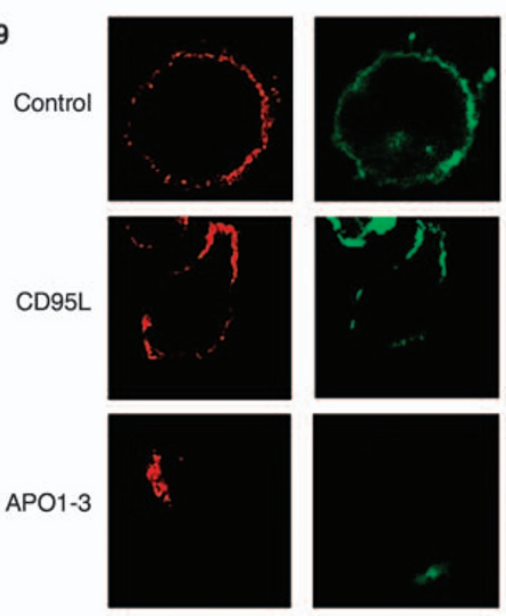
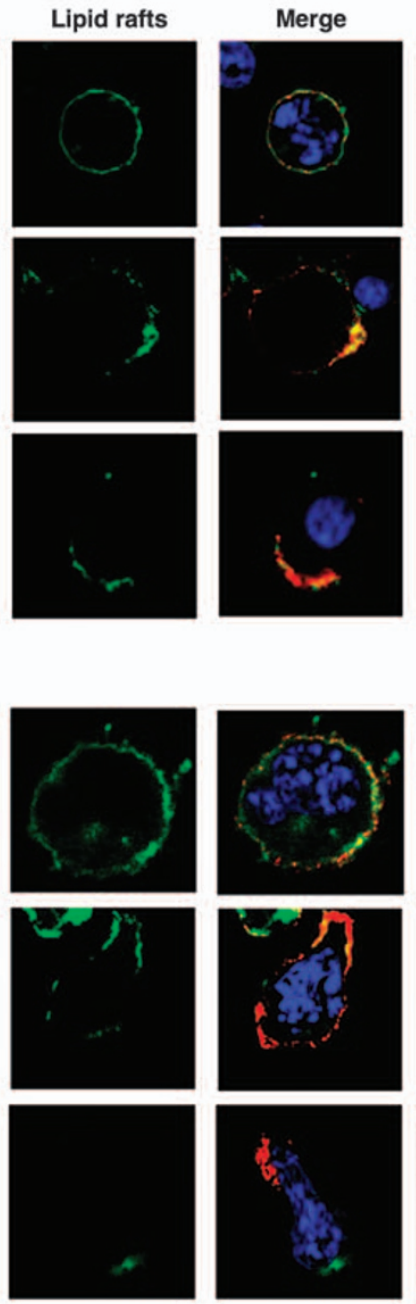

DIC
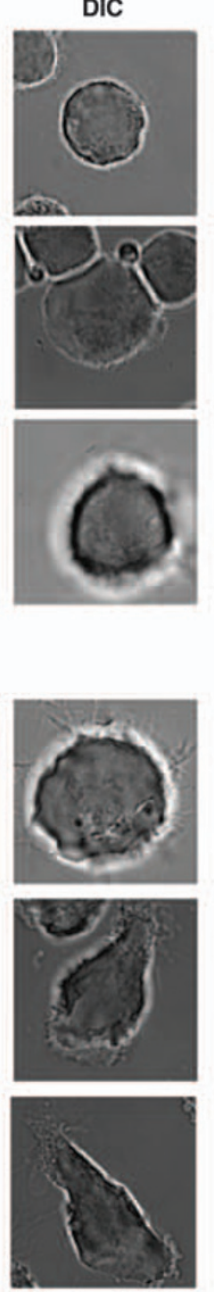
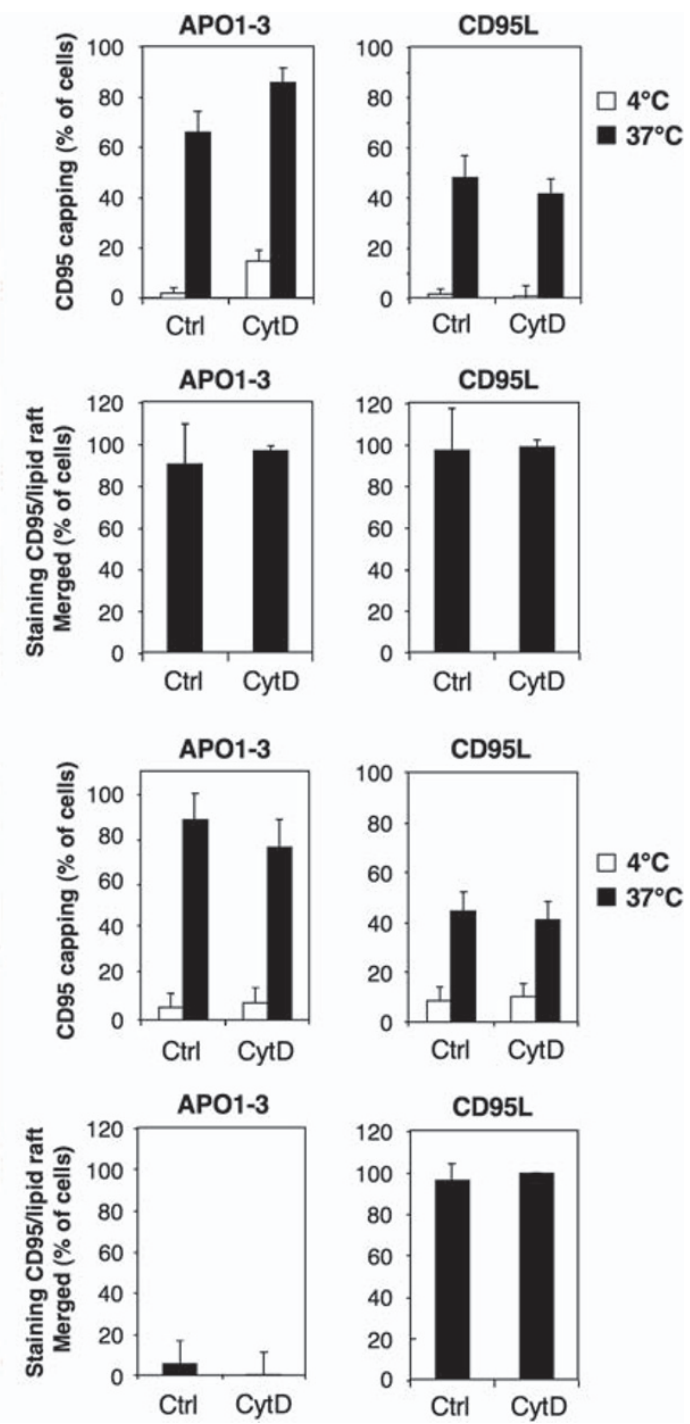

Figure 4 Actin is not responsible for the partition of CD95 into the lipid rafts. (a) Left panel; the type II cell line, Jurkat was treated with the agonist anti-CD95 APO1-3 $(1 \mu \mathrm{g} / \mathrm{ml})$ at $4^{\circ} \mathrm{C}$ for $30 \mathrm{~min}$ and then washed. Cells were next incubated at $4^{\circ} \mathrm{C}(0 \mathrm{~min})$ or at $37^{\circ} \mathrm{C}$ for $15 \mathrm{~min}$, fixed in PBS/PFA. CD95 was revealed with the secondary Alexa555-coupled Goat anti-mouse mAb (red) and lipids rafts were stained using a FITC-conjugated cholera toxin subunit B (CTB) (green). Nuclei were stained with DAPI (blue). Right panel; the superimposed staining of CD95 with lipid rafts is depicted by yellow color. The proportion of cells exhibiting a CD95 clustering was counted ( $n>300$ ). Among this latter cell population, the colocalization of CD95 clusters within lipid rafts was assessed. (b) The type I cell line H9 was treated as described above

have any relationship with the clustering of CD95 and on the formation of the CD95 microaggregates.

It is noteworthy that the CD95 microaggregates did not occur in type II cells stimulated with APO1-3, whereas the high molecular weight complex was observed on addition of the antiCD95 agonistic antibody 7C11 (see Supplementary Figure 2a). Furthermore, the $7 \mathrm{C} 11$-induced apoptotic signal remained totally unaffected by the inhibition of actin polymerization in type I cells (see Supplementary Figure 2b). Taken together, these data suggested that in contrast to CD95L and agonistic antibody 7C11 stimulations, APO1-3 orchestrates the induction of a specific and unconventional CD95-mediated apoptotic signal that relies on actin remodeling in type I cells.

Actin polymerization does not prevent the redistribution of CD95 into lipid rafts. The membrane bilayer is depicted as a heterogeneous structure containing compacted proteo-lipidic assemblies that float into the rest of the more fluid membrane. ${ }^{19}$ These subdomains are enriched in sphingolipids and cholesterol and they are currently designated as glycosphingolipid-enriched microdomains, lipid rafts or simply microdomains. We and others have reported earlier that the redistribution of CD95 into lipid rafts was an early and crucial step to provide a stabilized surrounding for the DISC formation and the induction of the apoptotic signal. ${ }^{20-23}$ We simultaneously followed CD95 and the lipid rafts by staining cells with an anti-CD95 mAb and the FITC-coupled CTB, respectively. To address the question whether CD95 and lipid rafts were colocalized, three different approaches (that is, cytofluorogram, linescan, 2-D x/y-views of z-stacks and 3D reconstruction of z-stacks) were combined whose results are described in the Supplementary Figures 3, 4 and 5. Cytofluorogram, 2D-projection and 3D-reconstruction of z-stacks clearly indicated that pixels and voxels of the two 
a
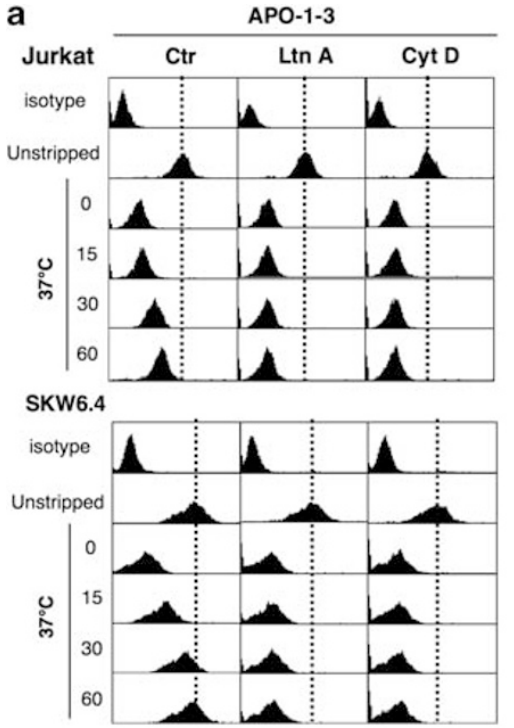

b
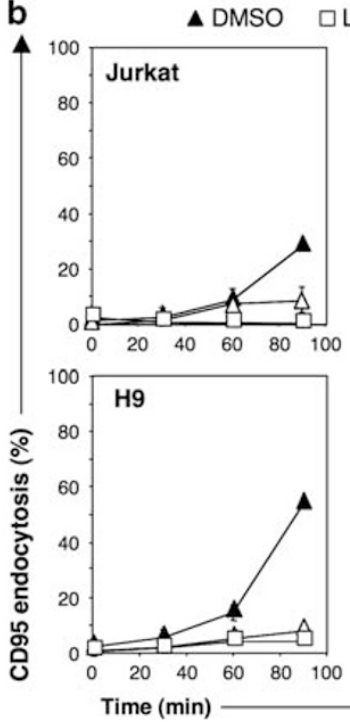
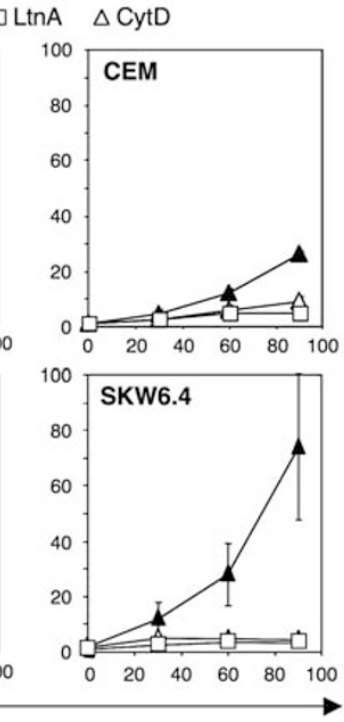

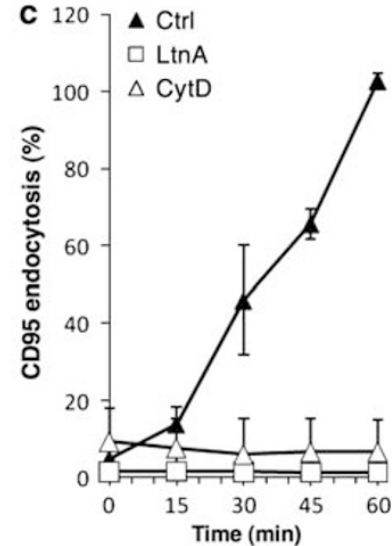

Figure 5 Internalization of CD95 induced by AP01-3 relies on the actin cytoskeleton. (a) Type I (SKW6.4) or type II (Jurkat) cells were treated with either latrunculin A $(\mathrm{LtnA}, 2.5 \mu \mathrm{M})$, cytochalasin D (CytD, $5 \mu \mathrm{M})$ or DMSO for $30 \mathrm{~min}$. Cells were then incubated with AP01-3 $(1 \mu \mathrm{g} / \mathrm{ml})$ for 30 min at $4^{\circ} \mathrm{C}$, washed and then stained with an Alexa488-conjugated anti-lgG3 mAb for $30 \mathrm{~min}$ at $4^{\circ} \mathrm{C}$. Cells were washed and incubated at $37^{\circ} \mathrm{C}$ for the indicated times. Cells were then incubated in presence (stripped) or not (unstripped) of an acidic buffer removing the surface-bound antibodies. Fluorescence of the internalized antibodies was assessed by flow cytometry. (b) The histograms depict the percentage of CD95 internalization induced upon AP01-3 stimulation in the indicated type I (H9, SKW6.4) or type II cells (Jurkat, CEM). (c) Activated PBTs were treated as described in (a). Percentage of AP01-3 induced CD95 endocytosis in activated PBTs. Results shown represent the mean \pm S.D. of three independently performed experiments

fluorochromes were superimposed in the type II cell line Jurkat stimulated with both CD95L and APO1-3 (Figure 4a, Supplementary Figures 3 and 5 and Supplementary movies 1, 2 and 3). On the other hand, although the addition of CD95L efficiently partitioned CD95 into lipid rafts in the type I cell line H9, APO1-3 stimulation was unable to merge the cluster of CD95 with the lipid rafts (see Figure 4b, Supplementary Figures 4 and 5 and Supplementary movies 4, 5 and 6). Strikingly, the inhibition of the actin polymerization remained useless to impede the partition of CD95 into the lipid rafts (Supplementary Figures 3 and 4), ruling out a role for actin in this process. We next quantified the proportion of cells showing a CD95 capping merged with the lipid rafts (Figure $4 a$ and b, right panels). This confirmed that the redistribution of CD95 into the lipid rafts proceeded independently of actin as CytD (Figure $4 \mathrm{a}$ and $\mathrm{b}$, right panels) and LtnA (data not shown) did not alter the partition of the death receptor into the lipid rafts observed on the CD95L stimulation (all cells) or the addition of APO1-3 (only in the type II cells).

CD95L is unable to induce CD95 internalization. As the engagement of CD95 drives the internalization of the receptor, ${ }^{11}$ we next studied the function of $\mathrm{F}$-actin in the endocytosis process. To quantify CD95 internalization, cells were incubated with APO1-3 (IgG3) or the recombinant FLAGCD95L. The cells were next stained with an Alexa488conjugated anti-IgG3 or anti-FLAG mAb on ice to prevent endocytosis and intensively washed (see Materials and Methods section). Cells were kept on ice (minimun endocytosis) or incubated at $37^{\circ} \mathrm{C}$ to allow internalization. After each incubation time, the stained CD95L or AP01-3 remaining at the plasma membrane were stripped using an acid buffer, whereas the internalized and fluorescent CD95 was quantified by flow cytometry analysis. Unstripped cells represented the maximum staining. Acid stripping removed almost all bound antibody present at the surface of the cells maintained on ice validating the relevance of this assay to assess CD95 internalization (Figure $5 \mathrm{a}$ ). Within $15 \mathrm{~min}$ after incubation at $37^{\circ} \mathrm{C}$, both type I and type II cells underwent endocytosis of CD95 when stimulated with the agonist mAb APO1-3 (Figure $5 a$ and b). The type I cells rapidly internalized a large number of CD95 receptors, whereas the process in the type II cells was delayed and to a lesser extent (Figure $5 \mathrm{a}$ and b). Both LtnA and CytD abrogated the CD95 endocytosis induced by APO1-3 in both type I and type II cells (Figure 5a and $\mathrm{b}$ ), indicating that $\mathrm{F}$-actin had an essential role in the internalization of CD95. On APO1-3 stimulation, PHAactivated PBTs underwent strong internalization of CD95, which was abrogated by the inhibition of actin polymerization (Figure 5c). Dynamin is crucial for the formation of clathrincoated vesicles. This GTPase is required for membrane budding at a late stage during the transition from a formed pit to a pinched-off vesicle. Similar to inhibitors of actin polymerization, the selective dynamin inhibitor dynasore ${ }^{24}$ altered CD95 internalization in both type I and type II cells (Supplementary Figure 6). These findings confirmed that the agonistic antibody triggered a dynamin/clathrin-dependent endocytosis of CD95 in both type I and type II cells. It is noteworthy that in type II cells, inhibitors of the actin polymerization completely abrogated the CD95 internalization, whereas they did not modify the apoptotic signal occurring on APO1-3 stimulation (see Figure 1b), indicating that in type II cells, the endocytosis process may drive a faint apoptotic signal 'masked' by a potent actin-independent pathway or rather may participate in the induction of non-apoptotic signals. 
a Jurkat (type II)

isotype Unstripped

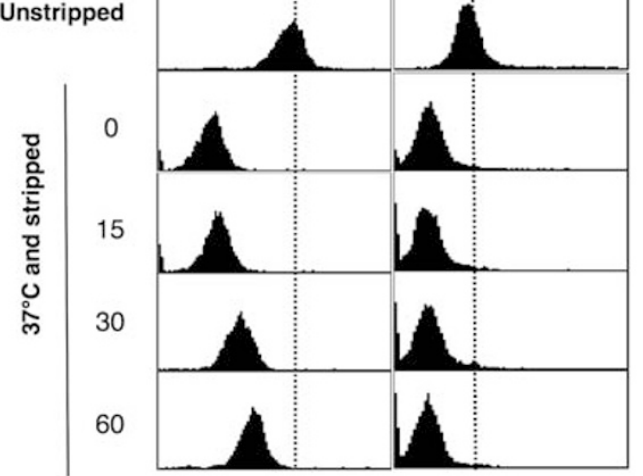

SKW6.4 (type I)

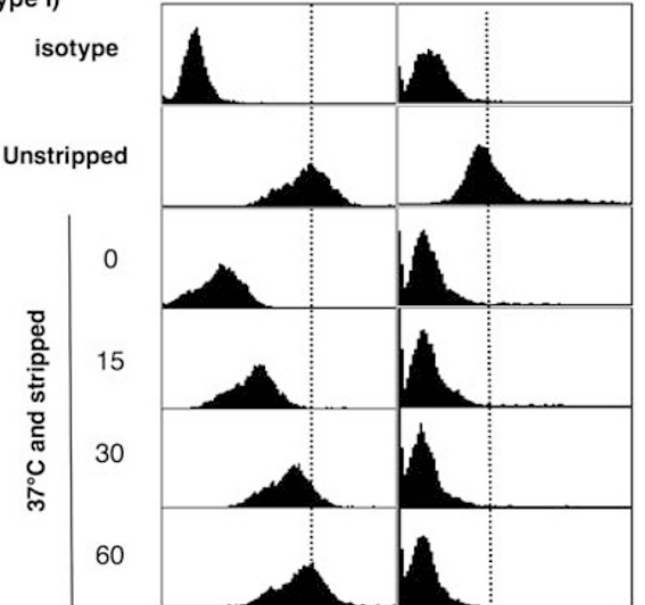

b
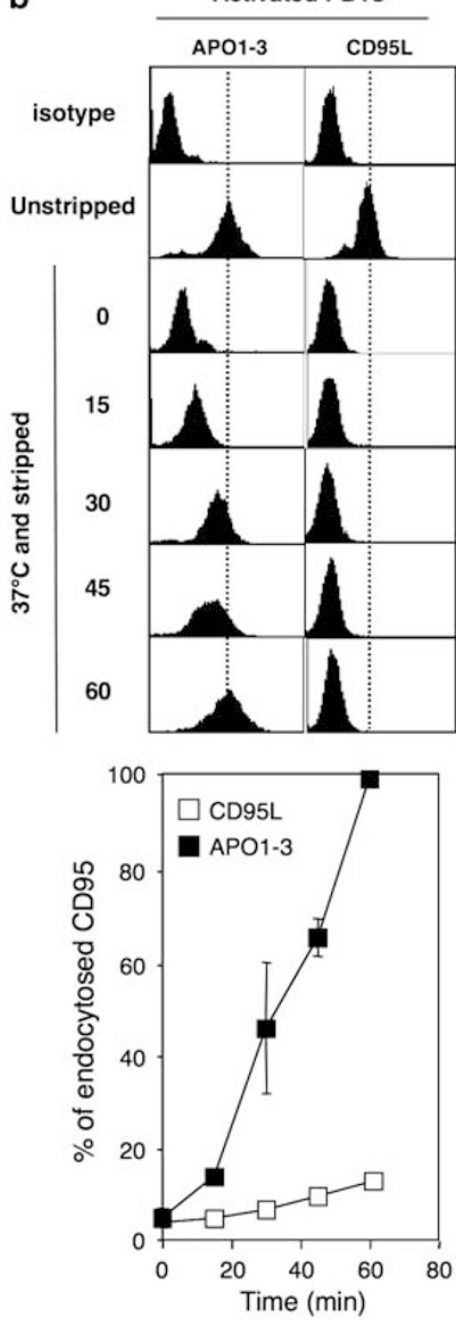

Figure 6 CD95L does not trigger internalization of CD95. (a) Type I (SKW6.4) or type II (Jurkat) cells were incubated with APO1-3 (1 $\mu \mathrm{g} / \mathrm{ml})$ or FLAG-CD95L (100 ng/ml) for $30 \mathrm{~min}$ at $4{ }^{\circ} \mathrm{C}$. Cells were washed and AP01-3 or CD95L were revealed using secondary Alexa488-coupled anti-lgG3 or anti-FLAG mAbs, respectively, for 30 min at $4{ }^{\circ} \mathrm{C}$. Stained cells were washed and incubated at $37^{\circ} \mathrm{C}$ for indicated times. Cells were stripped, or not with an acidic buffer and fluorescence of internalized ligands was quantified by flow cytometry. (b) Activated PBTs were treated as described in (a). Results shown represent the mean \pm S.D. of three independently carried out experiments

As CD95L triggered an apoptotic signal independent of the actin cytoskeleton remodeling, we next examined whether CD95L was able to internalize CD95. Strikingly, we did not observe any trace of CD95 endocytosis on addition of CD95L in both type II and type I cells (Figure 6a). In addition and despite their sensitivity toward the addition of CD95L (Figure 2a), the activated $\mathrm{T}$ lymphocytes (PBTs) did not internalize CD95 on the addition of the apoptotic ligand (Figure 6b). It was envisioned that CD95L might be unable to internalize CD95 because of its low concentration used compared with APO1-3. To rule out this possibility, we raised the CD95L concentration from $100 \mathrm{ng} / \mathrm{ml}$ to $1 \mu \mathrm{g} / \mathrm{ml}$. As the molecular weight of an IgG3 is five times heavier than that of the monomeric FLAG-CD95L (150 kDa for APO1-3 versus $30 \mathrm{kDa}$ for the FLAG-CD95L), $1 \mu \mathrm{g} / \mathrm{ml}$ of APO1-3 roughly represents five times less moles than $1 \mu \mathrm{g} / \mathrm{ml}$ of the FLAGCD95L (6.5 $\mu \mathrm{M}$ for AP01-3 versus 33.3 $\mu \mathrm{M}$ for CD95L). An increase in the CD95L amount remained useless to internalize CD95 (data not shown). In addition, the death receptor did not undergo endocytosis on longer incubation (90-min time point) with CD95L (data not shown). Taken together, these findings indicated that although APO1-3 stimulation showed an actindependent endocytosis of CD95, CD95L was unable to internalize the death receptor.

DISC formation and caspase-8 activation rely on actin remodeling in type I cells stimulated by APO1-3. As clathrin-dependent endocytosis of CD95 has been found to be mandatory for the formation of the DISC in type I cells, ${ }^{11}$ we therefore examined the effect of F-actin disruption on the DISC formation on APO1-3 stimulation in both type I and type II cells. As reported earlier, ${ }^{17}$ the pre-incubation of type I cells (H9, SKW6.4) with CytD or LtnA dramatically impaired the recruitment at the CD95 level of FADD and the procaspase-8 (Figure 7a and Supplementary Figure 7a). Furthermore, in type I cells, disruption of the actin network dramatically impaired the first step of the caspase- 8 activation, as evaluated by the cleavage of the small 
a
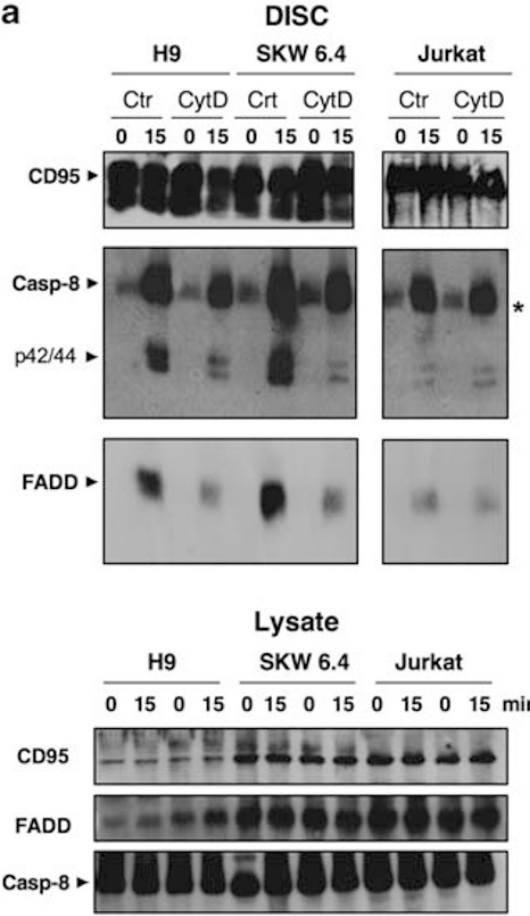

b
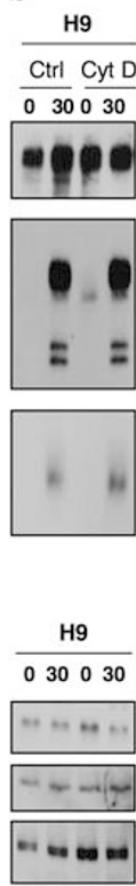

DISC
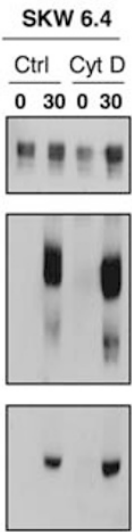

\section{Lysate}

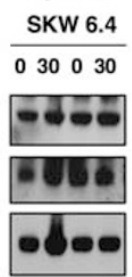

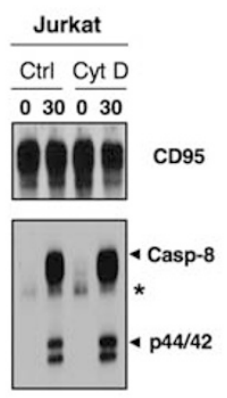

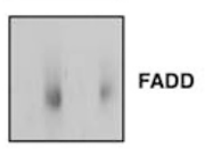

FADD

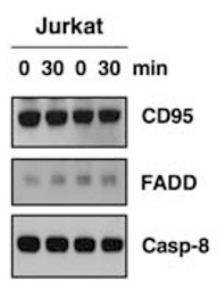

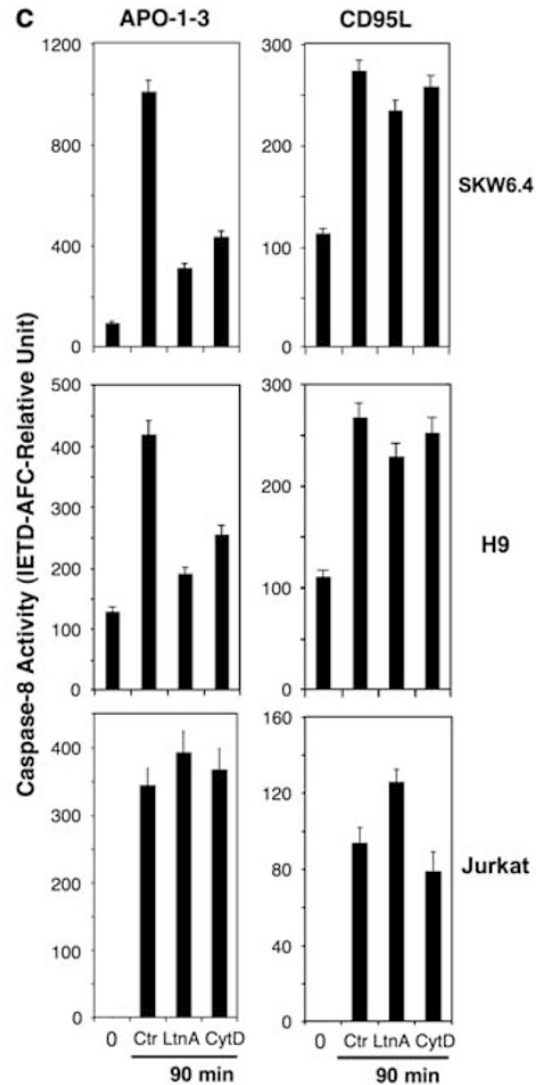

Figure 7 DISC formation and caspase-8 activity rely on actin reorganization only in type I cells stimulated by APO1-3. (a) The cells were treated with $5 \mu \mathrm{M}$ of cytochalasin $D$ (CytD) or DMSO for $30 \mathrm{~min}$ at $37^{\circ} \mathrm{C}$. Cells were then incubated for $15 \mathrm{~min}$ at $4^{\circ} \mathrm{C}(0 \mathrm{~min})$ or $37^{\circ} \mathrm{C}(15 \mathrm{~min})$ with APO1-3 $(1 \mu \mathrm{g} / \mathrm{ml})$. Cells were next washed, lysed and CD95 was immunoprecipitated using protein A-Sepharose beads. After extensive washing, the immune complex and the total lysate were resolved in a $12 \%$ SDS-PAGE and analyzed by immunoblots using specific antibodies. (b) Indicated cells were pre-incubated for $30 \mathrm{~min}$ with $5 \mu \mathrm{M}$ of CytD and then treated for $30 \mathrm{~min}$ with $100 \mathrm{ng} / \mathrm{ml}$ of CD95L at $4^{\circ} \mathrm{C}(0 \mathrm{~min})$ or $37^{\circ} \mathrm{C}(30 \mathrm{~min})$. Cells were lysed and CD95 was immunoprecipitated using the anti-CD95 AP01-3 with protein A-coupled sepharose beads. The immune complex was resolved by SDS-PAGE and the immunoblots were performed using the indicated antibodies. (a and $\mathbf{b})$ Asterisks depict irrelevant staining (APO1-3 heavy chain). (c) Cells were treated with CytD $(5 \mu \mathrm{M})$, LtnA $(2.5 \mu \mathrm{M})$ or DMSO for $30 \mathrm{~min}$ at $37^{\circ} \mathrm{C}$. Cells were then incubated with either soluble CD95L (100 ng/ml) or APO1-3 $(1 \mu \mathrm{g} / \mathrm{ml})$ for the indicated times. Cells were next lysed and incubated with lle-Glu-Thr-Asp-AFC, the substrate of the caspase- 8 . The catalytic activity of the caspase-8 was assessed by the quantification at $505 \mathrm{~nm}$ of the released fluorochrome AFC. Results represented the mean \pm S.D. of three independently performed experiments

subunit and the appearance of the p42/44 caspase-8 fragment. These data pinpointed that actin had a pivotal function in the DISC formation induced by the addition of APO1-3 in type I cells. In contrast, in the type II cell line Jurkat, the disruption of the actin cytoskeleton network did not alter the DISC formed (Figure 7a and Supplementary Figure 7a). Afterward, we investigated the effect of the actin cytoskeleton on the CD95L-mediated DISC formation. As depicted in Figure $7 \mathrm{~b}$ and Supplementary Figure 7b, inhibitors of actin polymerization did not affect the DISC formed on the addition of CD95L in both type I and type II cells.

Finally, to accurately quantify the effect of actin toward the caspase-8 activity, we carried out a caspase-8 cleavage assay. The type I cells stimulated by the agonistic antibody APO1-3 underwent activation of the initiator caspase-8, which was reduced close to its basal level on inhibition of actin polymerization (Figure 7c). Conversely, inhibitors of actin polymerization did not exert any role on the CD95L-induced caspase-8 activation both in type I (H9, SKW6.4) and type II (Jurkat) cells. Confirming the DISC analysis in the Jurkat cell line, APO1-3 activated caspase-8 independently of the actin cytoskeleton in the type II cell (Figure 7c). Altogether, these findings showed that except for type I cells/APO1-3 stimulation, F-actin did not have a major role during the CD95mediated apoptotic pathway.

\section{Discussion}

Herein, we show for the first time that the disruption of F-actin dramatically impairs the apoptotic signal induced by the agonist antibody APO1-3, whereas it does not affect the signal triggered by both soluble and membrane-bound CD95L. The role of actin in the CD95 signal remains complex as it depends on both the type of cell (type I versus type II) and the type of cell death inducer applied. Indeed, the inhibition of actin polymerization does not impinge on the CD95L-induced apoptotic signal, whereas it efficiently abrogates the APO1-3 mediated apoptotic signal in type I cells but not in type II cells. This study confirmed that the internalization of CD95 is implicated in the formation of the DISC in type I cells; ${ }^{11}$ nevertheless, this process is only involved in agonist antibody APO1-3 stimulation. Indeed, the inhibition of the actin polymerization does not impinge on the formation of the DISC 
and the activity of the initiator caspase-8 induced by the addition of CD95L in both type I and type II cells. In addition, the characterization of initial steps of the CD95 molecular ordering includes a supplementary complexity as, unlike APO1-3, another agonistic antibody 7C11 was unable to drive the actin-dependent apoptotic signal in type I cells (Supplementary Figure 2b). These findings support that APO1-3 generates a highly specific and unconventional ('non-canonical') CD95 signaling pathway that diverges from the 'canonical' CD95Linduced signal before the recruitment of FADD and the DISC formation.

The actin cytoskeleton is not implicated in the redistribution of CD95 into the lipid rafts, confirming a recent study showing that the adaptor protein termed ezrin, which links CD95 to the actin cytoskeleton, was not involved in the partitioning of CD95 into the lipid rafts. ${ }^{25}$ The same authors found that the redistribution of CD95 into lipid rafts was a prerequisite for its internalization in mouse $\mathrm{T}$ cells. Our results challenge this statement as in our hands the partition of CD95 into the lipid rafts observed with $C D 95 \mathrm{~L}$ does not lead to the internalization of the death receptor, and besides, the APO1-3 stimulation does not partition CD95 into the lipid rafts in type I cells despite the potent internalization of the receptor. As a whole, these results suggest that CD95 can undergo three different fates on stimulation: (i) its redistribution into the lipid rafts with a delayed endocytosis (type II/APO1-3), (ii) its redistribution into the lipid rafts without endocytosis (all cells/CD95L) or (iii) no relocalization into the microdomains but a rapid and potent internalization (type I/APO1-3) (Figure 8). Finally, these findings are in agreement with a report on TRAIL, which, akin to CD95L, transmits a death signal independently of clathrindependent internalization of the receptor. ${ }^{26}$

Our results are in contradiction with the data obtained with the death receptor CD95 ${ }^{17,25,27}$ and TNF-R1. ${ }^{28}$ The discrepancy could be due to the fact that experiments have been performed almost exclusively with agonistic antibodies ${ }^{17}$ or to the differences that may exist in the CD95 signal between mouse and human T cells. ${ }^{25}$ It is noteworthy that some authors studied the internalization of CD95 by quantifying CD95 remnants on the cell surface after incubation with agonistic antibodies or the soluble CD95L. In these conditions, we cannot rule out that the formation of the CD95 microaggregates and/or the redistribution of CD95 into the lipid raft-containing platform may modify the accessibility of the antibody toward the CD95 epitopes by cofactors or membrane invaginations and hence may diminish the staining. The decreased staining of the cells could be interpreted as a false-positive internalization of CD95. Furthermore, a recent study revealed that the engagement of CD95 dramatically increases the general and nonspecific membrane trafficking. ${ }^{29}$ This observation underlines the essential step of cell washing to avoid the nonspecific internalization of the unbound fluorescent-coupled antibodies or ligands present in the medium.

Accumulating evidence supports that the agonistic antibodies should be eliminated from further studies as they trigger a non-physiological and unconventional CD95 signaling pathway. However we cannot rule out the possibility that the formation of the CD95 microaggregates, the exclusion of CD95 from the lipid rafts and the subsequent cell death signal dependent of the actin remodeling corresponded with a CD95

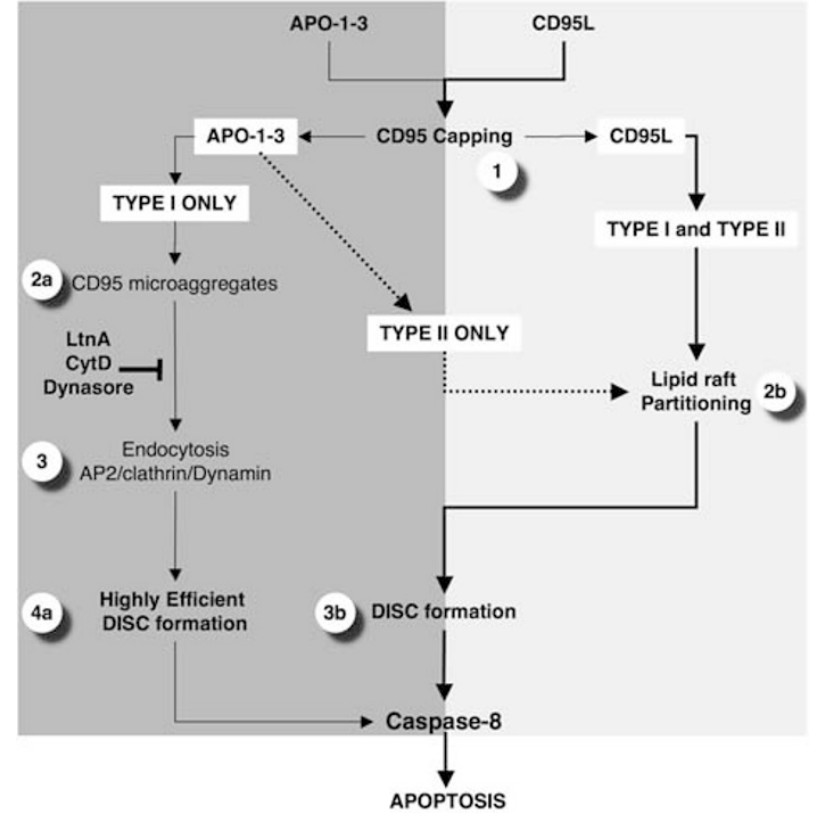

Figure 8 Schematic representation of the actin-dependent and -independent signaling pathways triggered upon the APO1-3 and CD95L stimulations. Latrunculin A (LtnA), Cytochalasin D (CytD) and Dynasore prevent CD95 internalization. The thin line represents the 'unconventional' AP01-3-induced apoptotic signal. In type II cells, APO1-3 stimulation enables the partition of CD95 into the lipid rafts and inhibitors of the actin polymerization are useless to cripple the apoptotic signal (thick and dotted line). The thick line depicts the direct and 'canonical' apoptotic signal induced by addition of CD95L. Numbers in the gray circles represent the molecular ordering of CD95 signal

alternative signaling pathway masked by a principal actinindependent pathway. As summarized in Figure 8, the agonist antibody APO1-3 propagates an indirect (four steps required before the activation of caspase-8) and marginal apoptotic signal, whereas CD95L triggers a direct (three steps) and potent apoptotic signal.

In contrast to CD95L, the CD95 capping and its redistribution into the lipid rafts occurred in cells treated with antitumoral agents such as aplidin, ${ }^{30}$ edelfosine ${ }^{31,32}$ or semaphorin $3 A^{33}$ and relied on the actin cytoskeleton remodeling. The partition of CD95 into the lipid rafts and the subsequent induction of the apoptotic signal observed in cells treated with various antitumoral agents such as cisplatin, ${ }^{34}$ edelfosine $^{31,32}$ or resveratrol $^{35}$ occurred independent of ligand expression. These studies suggest that the abovementioned chemicals promote the redistribution of CD95 into lipid rafts through the induction and/or the inhibition of intracellular signals and the ligand-independent reorganization of the actin cytoskeleton. Yet the question remains as to how the CD95L-induced stimulus bypasses the requirement for actin to cluster CD95 and/or to redistribute it into lipid rafts. One potential explanation could be the modulation of the membrane fluidity. Indeed, cisplatin triggered the capping of CD95 and its partitioning into the lipid rafts through the inhibition of $\mathrm{Na}^{+} / \mathrm{H}^{+}$exchanger isoform 1 activity. ${ }^{36}$ Inhibition of proton homeostasis leads to a general increase of the membrane fluidity, which is essential to aggregate lipid rafts $^{37}$ and which could account for the actin-independent distribution of CD95 into the lipid rafts on CD95L treatment. 


\section{Materials and Methods}

Cell lines and peripheral blood lymphocytes. The human leukemic T-cell lines Jurkat and CEM, the lymphoma T-cell line H9 and the Epstein-Barr virus-transformed B-cell line SKW6.4 were maintained in RPMI supplemented with $8 \% \mathrm{v} / \mathrm{v}$ heat-inactivated $\mathrm{FCS}$ and $2 \mathrm{mM} \mathrm{L-glutamine}$ at $37^{\circ} \mathrm{C}$ in a $5 \% \mathrm{CO}_{2}$ incubator. Peripheral blood mononuclear cells from healthy donors were isolated by Ficoll centrifugation, washed twice in phosphate-buffered saline (PBS). Monocytes were removed by $\mathrm{a} 2 \mathrm{~h}$ adherence step and the naive peripheral blood lymphocytes were incubated overnight in RPMl supplemented with $1 \mu \mathrm{g} / \mathrm{ml}$ of PHA (Sigma-Aldrich, L'Isle-d'Abeau-Chesnes, France). Cells were washed extensively and incubated in the culture medium supplemented with $100 \mathrm{U} / \mathrm{ml}$ of recombinant IL-2 (R\&D, Minneapolis, MN, USA) for 6 days. The mouse T-lymphoma cell line $1 \mathrm{~A} 12$ expressing membrane CD95L was kindly provided by $\operatorname{Pr} S$ Nagata (Osaka Bioscience Institute, Osaka, Japan).

Antibodies and other reagents. Cytochalasin $D$, latrunculin $A$, anti-FLAG mAb (clone M2), DAPI (4',6-diamidino-2-phenylindole), FITC-conjugated cholera toxin B (CTB) subunit, FITC-coupled phalloidin and DiOC6 $\left(3,3^{\prime}\right.$ dihexyloxacarbocyanine iodide) were purchased from Sigma-Aldrich. The homemade soluble CD95L (gp190-CD95L) was generated in the laboratory. ${ }^{15}$ The anti-leukemia inhibitory factor isotype-matched negative control $1 \mathrm{~F} 10(\mathrm{lgG})$ $\mathrm{mAb}$ was generated in the laboratory. Anti-caspase-8 (C15), anti-CD95 mAb (AP01-3), human recombinant CD95L (FLAG-tagged CD95L) were purchased from Axxora (Coger S.A., Paris, France). Anti-human CD95 mAb (DX2) and anti-human FADD mAb (Clone 1) were purchased from BD Biosciences (Le Pont de Claix, France). The anti-CD95 mAb C-20 was purchased from Santa Cruz Biotechnology (Santa Cruz, CA, USA). Alexa647-coupled wheat germ agglutinine (WGA) was purchased from Molecular Probes (Invitrogen, Cergy Pontoise, France).

Cell death assay. Cell viability was assessed using MTT (3-(4,5dimethylthiazol-2-yl)-2,5-diphenyltetrazolium bromide) assay, exactly as described earlier. ${ }^{38}$ In brief, $4.10^{4}$ cells were cultured for $24 \mathrm{~h}$ in flat-bottom 96 -well plates with the indicated concentrations of the apoptosis inducer in a final volume of $100 \mu \mathrm{l}$. A volume of $15 \mu \mathrm{l}$ of MTT ( $5 \mathrm{mg} / \mathrm{ml}$ in PBS) solution were added, and after $4 \mathrm{~h}$ of incubation at $37^{\circ} \mathrm{C}$, the absorbance was measured at $570 \mathrm{~nm}$ wavelength using the Titertek Labsystems Multiskan reader (Turku, Finland).

Cell death was also assessed by the measure of the loss of mitochondrial potential $\left(\Delta \psi_{\mathrm{m}}\right)$. Cells were pre-incubated with DiOC6 $(10 \mathrm{nM})$ for $15 \mathrm{~min}$ and then stimulated with CD95L or AP01-3. Cell fluorescence was measured by flow cytometry using a CANTO II cytometer (BD Biosciences).

The cytotoxic activity of the membrane-bound CD95L-expressing (1A12) cells was assessed using a ${ }^{51} \mathrm{Cr}$-release assay. The target cells were loaded with $50 \mu \mathrm{Cl}$ of ${ }^{51} \mathrm{Cr}$ (Perkin Elmer, Waltham, MA, USA) per $10^{6}$ cells, for $1 \mathrm{~h}$ at $37^{\circ} \mathrm{C}$. Cells were washed and dispensed in round-bottomed 96 -well plates ( 4.103 cells per well). The CD95L-expressing effector cells (1A12 cells) were mixed at the indicated ratios in a total volume of $100 \mu$ l. Cells were incubated for the indicated times at $37^{\circ} \mathrm{C}$ and then $25 \mu \mathrm{l}$ of the supernatant was harvested and mixed with $15 \mu \mathrm{l}$ of scintillation liquid. The released radioactivity was quantified using a MicroBeta Trilux beta counter (Wallac, Turku, Finland). Spontaneous ${ }^{51} \mathrm{Cr}$ release corresponded to the target cells incubated in culture medium, whereas the maximum release was assessed by incubating target cells in a volume of distilled water containing $1 \%$ Triton X-100. The percentage of ${ }^{51} \mathrm{Cr}$ release was calculated as follows: [(experimental ${ }^{51} \mathrm{Cr}$ release-spontaneous ${ }^{51} \mathrm{Cr}$ release)/(maximum ${ }^{51} \mathrm{Cr}$ release-spontaneous ${ }^{51} \mathrm{Cr}$ release) $] \times 100$.

Detergent lysis experiments and western blot analysis. Cells were lysed for $30 \mathrm{~min}$ at $4{ }^{\circ} \mathrm{C}$ in lysis buffer $(25 \mathrm{mM}$ HEPES pH 7.4, 1\% v/v Triton X-100, $150 \mathrm{mM} \mathrm{NaCl}, 2 \mathrm{mM}$ EGTA supplemented with a mix of protease inhibitors (SigmaAldrich)). Protein concentration was determined by the bicinchoninic acid method (PIERCE, Rockford, IL, USA) according to the manufacturer's protocol. Proteins were separated on a $12 \%$ SDS-PAGE and transferred to a nitrocellulose membrane (GE Healthcare, Buckinghamshire, England). The membrane was blocked for $15 \mathrm{~min}$ with TBST $(50 \mathrm{mM}$ Tris, $160 \mathrm{mM} \mathrm{NaCl}, 0.05 \% \mathrm{v} / \mathrm{v}$ Tween $20, \mathrm{pH} 7.8$ ) containing $5 \% \mathrm{w} / \mathrm{v}$ dried skimmed milk (TBSTM). Primary antibody was incubated overnight at $4^{\circ} \mathrm{C}$ in TBSTM. The membrane was intensively washed (TBST) and then the peroxydase-labeled anti-rabbit (Zymed Laboratories, San Francisco, CA, USA) or anti-mouse (GE Healthcare) was added for $45 \mathrm{~min}$. The proteins were visualized with the enhanced chemiluminescence substrate kit (ECL, GE Healthcare)
DISC analysis. Cells $10.10^{6}$ (H9 and SKW6.4) or $20.10^{6}$ (Jurkat) were preincubated with CytD $(5 \mu \mathrm{M})$, LtnA $(2.5 \mu \mathrm{M})$ or DMSO for 30 min. Cells were then incubated with $1 \mu \mathrm{g} / \mathrm{ml}$ of APO1-3 for $15 \mathrm{~min}$ at $4^{\circ} \mathrm{C}$ or at $37^{\circ} \mathrm{C}$ and subsequently lysed for $30 \mathrm{~min}$ at $4^{\circ} \mathrm{C}$ in lysis buffer. CD95 was immunoprecipitated using protein A-sepharose beads (GE Healthcare) for $2 \mathrm{~h}$. To explore the DISC formed on addition of CD95L, cells were pre-incubated with CytD and LtnA, as described above, and then stimulated for $30 \mathrm{~min}$ at $37^{\circ} \mathrm{C}$ with $100 \mathrm{ng} / \mathrm{ml}$ of FLAG-CD95L. The cells were then lysed, $1 \mu \mathrm{g}$ of AP01-3 was added to the lysate and CD95 was immunoprecipitated using protein A-sepharose beads. After extensive washing, the immune complex was resolved using a $12 \%$ SDS-PAGE.

Endocytosis assay. Cells were incubated at $4^{\circ} \mathrm{C}$ for $30 \mathrm{~min}$ with a solution containing both FLAG-CD95L and an FITC-coupled anti-FLAG mAb or with APO-13 (IgG3) mAb or with a isotype-matched control $\mathrm{mAb}$, washed and then stained with an Alexa488-conjugated anti-IgG mAb. Cells were washed in PBS and incubated for the indicated time at $37^{\circ} \mathrm{C}$, and then were treated or untreated with a stripping buffer $(0.2 \mathrm{M} \mathrm{NaCl}, 0.2 \mathrm{M}$ acetic acid) eluting the membrane-bound antibodies and sparing the intracellular endocytosed fluorescent antibodies. For treatments with the inhibitors of actin cytoskeleton polymerization, cells were pre-incubated for $30 \mathrm{~min}$ with LtnA $(2.5 \mu \mathrm{M})$, CytD $(5 \mu \mathrm{M})$ or DMSO before CD95L or APO-1-3 incubation. Cells were resuspended in PBS and intracellular CD95 staining was analyzed with a CANTO II flow cytometer (BD Biosciences). The proportion of endocytosis was measured as follows: [(fluorescence intensity of stripped cells-Isotypic staining)/ (fluorescence intensity of unstripped cells-Isotypic staining)] $\times 100$.

Immunofluorescence imaging. Cells were allowed to adhere for $5 \mathrm{~min}$ at room temperature to poly-L-Lysine-coated slides and treated with LtnA, CytD or DMSO for $30 \mathrm{~min}$ at $37^{\circ} \mathrm{C}$. The cells were next stimulated with APO1-3 or CD95L for the indicated times $(0-30 \mathrm{~min})$ at $37^{\circ} \mathrm{C}$. After extensive washing, the cells were fixed in PBS containing $4 \% \mathrm{w} / \mathrm{v}$ paraformaldehyde for $15 \mathrm{~min}$. The aldehyde groups were quenched for 10 min using a solution of PBS supplemented with $5 \%$ FCS. The CD95L-stimulated cells were incubated with $1 \mu \mathrm{g} / \mathrm{ml}$ of APO1-3 for $30 \mathrm{~min}$ at $4^{\circ} \mathrm{C}$. Finally, in AP01-3- and CD95L-stimulated cells, CD95 was revealed using the Alexa555-conjugated goat anti-mouse antibody (Molecular Probes, Cergy Pontoise, France) in PBS $/ 1 \%$ w/v BSA for 30 min at $4^{\circ} \mathrm{C}$. Lipid rafts were tagged by FITClabeled CTB. Slides were washed with PBS, dried and mounted with Fluoroprep (Biomerieux, Marcy L'étoile, France). For plasma membrane staining, fixed cells were incubated for $10 \mathrm{~min}$ with $1 \mu \mathrm{g} / \mathrm{ml}$ Alexa647-linked WGA. Polymerized actin (F-actin) was stained as described elsewhere. ${ }^{39}$ Images were acquired with a confocal microscope TSC SP5 (Leica, Wetzlar, Germany) with a $\times 63$ objective.

Caspase activity measurement. After treatment, $1-2.10^{6}$ cells were lysed and incubated with the caspase-8 (lle-Glu-Thr-Asp (IETD)-AFC) substrate in a reaction buffer following the manufacturer's instructions (Biomol International, Plymouth Meeting, PA, USA). The cleavage of caspase substrates (release of the fluorochrome AFC) was quantified at $505 \mathrm{~nm}$ wavelength (excitation $400 \mathrm{~nm}$ ) over time using the Varioskan Flash spectral scanning multimode reader (Thermo Fisher Scientific, Watttham, MA, USA).

Acknowledgements. This work was supported by grants from Agence Nationale de la Recherche (ANR JC07_183182) and Ligue Contre le Cancer (Comités de la Dordogne and Comités des Pyrénées-Atlantiques). BCD is supported by the Fondation de France (postdoctoral fellowship Leucémie). PL is employed by INSERM. We are grateful to Philippe Legros (PICIN, University Bordeaux-2, Bordeaux) for his assistance in microscopy analyses.

1. Siegel RM, Frederiksen JK, Zacharias DA, Chan FK, Johnson M, Lynch D et al. Fas preassociation required for apoptosis signaling and dominant inhibition by pathogenic mutations. Science 2000; 288: 2354-2357.

2. Scott FL, Stec B, Pop C, Dobaczewska MK, Lee JJ, Monosov E et al. The Fas-FADD death domain complex structure unravels signalling by receptor clustering. Nature 2009; 457: 1019-1022.

3. Kayagaki N, Kawasaki A, Ebata T, Ohmoto H, Ikeda S, Inoue S et al. Metalloproteinasemediated release of human Fas ligand. J Exp Med 1995; 182: 1777-1783.

4. Kischkel FC, Hellbardt S, Behrmann I, Germer M, Pawlita M, Krammer PH et al. Cytotoxicity-dependent APO-1 (Fas/CD95)-associated proteins form a death-inducing signaling complex (DISC) with the receptor. EMBO J 1995; 14: 5579-5588.

5. Berke G. The CTL's kiss of death. Cell 1995; 81: 9-12. 
24. Macia E, Ehrlich M, Massol R, Boucrot E, Brunner C, Kirchhausen T. Dynasore, a cellpermeable inhibitor of dynamin. Dev Cell 2006; 10: 839-850.

Montel AH, Bochan MR, Hobbs JA, Lynch DH, Brahmi Z. Fas involvement in cytotoxicity mediated by human NK cells. Cell Immunol 1995; 166: 236-246.

7. Friesen C, Herr I, Krammer PH, Debatin KM. Involvement of the CD95 (APO-1/FAS) receptor/ligand system in drug-induced apoptosis in leukemia cells. Nat Med 1996; 2: 574-577.

8. Ross DT, Scherf U, Eisen MB, Perou CM, Rees C, Spellman P et al. Systematic variation in gene expression patterns in human cancer cell lines. Nat Genet 2000; 24: 227-235.

9. Boyer B, Valles AM, Edme N. Induction and regulation of epithelial-mesenchymal transitions. Biochem Pharmacol 2000; 60: 1091-1099.

10. Chaigne-Delalande B, Moreau JF, Legembre P. Rewinding the DISC. Arch Immunol Ther Exp (Warsz) 2008; 56: 9-14.

11. Lee KH, Feig C, Tchikov V, Schickel R, Hallas C, Schutze S et al. The role of receptor internalization in CD95 signaling. EMBO J 2006; 25: 1009-1023.

12. Celeste Morley S, Sun GP, Bierer BE. Inhibition of actin polymerization enhances commitment to and execution of apoptosis induced by withdrawal of trophic support. J Cell Biochem 2003; 88: 1066-1076.

13. Meng Y, Kang S, Fishman DA. Lysophosphatidic acid inhibits anti-Fas-mediated apoptosis enhanced by actin depolymerization in epithelial ovarian cancer. FEBS Lett 2005; $\mathbf{5 7 9}$ 1311-1319.

14. Huang DC, Hahne M, Schroeter M, Frei K, Fontana A, Villunger A et al. Activation of Fas by FasL induces apoptosis by a mechanism that cannot be blocked by $\mathrm{Bcl}-2$ or $\mathrm{Bcl}-\mathrm{x}(\mathrm{L})$. Proc Natl Acad Sci USA 1999; 96: 14871-14876.

15. Legembre $P$, Beneteau M, Daburon S, Moreau JF, Taupin JL. Cutting edge: SDS-stable Fas microaggregates: an early event of Fas activation occurring with agonistic anti-Fas antibody but not with Fas ligand. J Immunol 2003; 171: 5659-5662.

16. Thilenius AR, Braun K, Russell JH. Agonist antibody and Fas ligand mediate different sensitivity to death in the signaling pathways of Fas and cytoplasmic mutants. Eur $\mathrm{J}$ Immunol 1997; 27: 1108-1114.

17. Algeciras-Schimnich A, Shen L, Barnhart BC, Murmann AE, Burkhardt JK, Peter ME. Molecular ordering of the initial signaling events of CD95. Mol Cell Biol 2002; 22: 207-220.

18. Kamitani T, Nguyen HP, Yeh ET. Activation-induced aggregation and processing of the human Fas antigen. Detection with cytoplasmic domain-specific antibodies. J Biol Chem 1997; 272: 22307-22314.

19. Simons K, Toomre D. Lipid rafts and signal transduction. Nat Rev Mol Cell Biol 2000; 1: 31-39

20. Gajate $\mathrm{C}$, Mollinedo $\mathrm{F}$. The antitumor ether lipid ET-18-OCH(3) induces apoptosis through translocation and capping of Fas/CD95 into membrane rafts in human leukemic cells. Blood 2001; 98: 3860-3863.

21. Hueber AO, Bernard AM, Herincs Z, Couzinet A, He HT. An essential role for membrane rafts in the initiation of Fas/CD95-triggered cell death in mouse thymocytes. EMBO Rep 2002; 3: 190-196.

22. Legembre P, Daburon S, Moreau P, Ichas F, de Giorgi F, Moreau JF et al. Amplification of Fas-mediated apoptosis in type II cells via microdomain recruitment. Mol Cell Biol 2005; 25 6811-6820.

23. Muppidi JR, Siegel RM. Ligand-independent redistribution of Fas (CD95) into lipid rafts mediates clonotypic T cell death. Nat Immunol 2004; 5: 182-189.
25. Chakrabandhu K, Herincs Z, Huault S, Dost B, Peng L, Conchonaud F et al. Palmitoylation is required for efficient Fas cell death signaling. EMBO J 2007; 26: 209-220.

26. Kohlhaas SL, Craxton A, Sun XM, Pinkoski MJ, Cohen GM. Receptor-mediated endocytosis is not required for tumor necrosis factor-related apoptosis-inducing ligand (TRAIL)-induced apoptosis. J Biol Chem 2007; 282: 12831-12841.

27. Soderstrom TS, Nyberg SD, Eriksson JE. CD95 capping is ROCK-dependent and dispensable for apoptosis. J Cell Sci 2005; 118: 2211-2223.

28. Schneider-Brachert W, Tchikov V, Merkel O, Jakob M, Hallas C, Kruse ML et al. Inhibition of TNF receptor 1 internalization by adenovirus $14.7 \mathrm{~K}$ as a novel immune escape mechanism. J Clin Invest 2006; 116: 2901-2913.

29. Matarrese P, Manganelli V, Garofalo T, Tinari A, Gambardella L, Ndebele K et al. Endosomal compartment contributes to the propagation of CD95/Fas-mediated signals in type II cells. Biochem J 2008; 413: 467-478.

30. Gajate C, Mollinedo F. Cytoskeleton-mediated death receptor and ligand concentration in lipid rafts forms apoptosis-promoting clusters in cancer chemotherapy. J Biol Chem 2005: 280: 11641-11647.

31. Beneteau M, Pizon M, Chaigne-Delalande B, Daburon S, Moreau P, De Giorgi F et al. Localization of Fas/CD95 into the lipid rafts on down-modulation of the phosphatidylinosito 3-kinase signaling pathway. Mol Cancer Res 2008; 6: 604-613.

32. Gajate C, Mollinedo F. Edelfosine and perifosine induce selective apoptosis in multiple myeloma by recruitment of death receptors and downstream signaling molecules into lipid rafts. Blood 2007; 109: 711-719

33. Moretti S, Procopio A, Lazzarini R, Rippo MR, Testa R, Marra M et al. Semaphorin3A signaling controls Fas (CD95)-mediated apoptosis by promoting Fas translocation into lipid

34. Lacour S, Hammann A, Grazide S, Lagadic-Gossmann D, Athias A, Sergent 0 et al. Cisplatin-induced CD95 redistribution into membrane lipid rafts of HT29 human colon cancer cells. Cancer Res 2004; 64: 3593-3598.

35. Delmas D, Rebe C, Lacour S, Filomenko R, Athias A, Gambert P et al. Resveratrol-induced apoptosis is associated with Fas redistribution in the rafts and the formation of a deathinducing signaling complex in colon cancer cells. J Biol Chem 2003; 278: 41482-41490.

36. Rebillard A, Tekpli X, Meurette O, Sergent O, LeMoigne-Muller G, Vernhet $L$ et al. Cisplatin-induced apoptosis involves membrane fluidification via inhibition of NHE1 in human colon cancer cells. Cancer Res 2007; 67: 7865-7874.

37. Nourissat $\mathrm{P}$, Travert M, Chevanne M, Tekpli X, Rebillard A, Le Moigne-Muller G et al. Ethanol induces oxidative stress in primary rat hepatocytes through the early involvement of lipid raft clustering. Hepatology 2008; 47: 59-70.

38. Legembre P, Moreau P, Daburon S, Moreau JF, Taupin JL. Potentiation of Fas-mediated apoptosis by an engineered glycosylphosphatidylinositol-linked Fas. Cell Death Differ 2002; 9: 329-339.

39. Chaigne-Delalande B, Guidicelli G, Couzi L, Merville P, Mahfouf W, Bouchet S et al. The immunosuppressor mycophenolic acid kills activated lymphocytes by inducing a nonclassical actin-dependent necrotic signal. J Immunol 2008; 181: 7630-7638. rafts. Blood 2008; 111: 2290-2299. 